\title{
O PROCESSO DE ACESSO AO TRIPS, A RELAÇÃO DO ACORDO COM AS QUESTÕES DE SAÚDE PÚBLICA E A CDB E OS ACORDOS TRIPS-PLUS
}

Henrique da Silva Mercer ${ }^{1}$

\section{RESUMO}

Este trabalho procurar sintetizar as atuais discussões relativas ao TRIPS. Elas se dariam principalmente sobre quatro temas: como os países membros da OMC devem fazer para se adaptar às regras do TRIPS e como e por que aqueles que desejam ingressar na Organização devem fazê-lo; se o TRIPS é um obstáculo ou uma ferramenta a ser usada em prol da saúde pública; a existência ou não de um conflito entre o TRIPS e a CDB; e por fim os acordos TRIPS-plus e os riscos e oportunidades que eles oferecem aos países não desenvolvidos.

\section{ABSTRACT}

The present article aims to synthesize the most recent discussions concerning the TRIPS. They are basically four: what WTO members do to adapt their internal legislation to the TRIPS and how and why those countries whiling to join the Organization should do it, from TRIPS point of view; if TRIPS is an obstacle or a tool to be used to improve public health; the existence or not of a conflict between the TRIPS and de CBD; and the last one, the TRIPS-plus agreements and the risk and opportunities they represent for developing countries and LDCs.

Palavras chave: TRIPS, CDB, saúde pública.

Key-words: TRIPS, CBD, public health.

\footnotetext{
${ }^{1}$ Coordenador Jurídico da Casa Latino-Americana, CASLA.
}

Revista Brasileira de Direito Internacional, Curitiba, v.4, n.4, jul./dez.2006 


\section{INTRODUÇÃO}

Este artigo abordará alguns dos aspectos mais polêmicos do TRIPS, que são o processo de transição para as suas normativas do TRIPS e as relações entre esse acordo e a Convenção de Biodiversidade da ONU, de um lado, e as questões de saúde pública, de outro. Em seguida, analisará os chamados acordos TRIPS-Plus, principais destaques das questões futuras envolvendo o Acordo de Propriedade Intelectual da OMC.

\section{QUE É O TRIPS E O PROCESSO DE TRANSIÇÃO DOS PAÍSES MEMBROS AS SUAS REGULAMENTAÇÕES}

Na Rodada do Uruguai, celebrada durante a vigência do Acordo Geral sobre Tarifas e Comércio (GATT), fundou-se a Organização Mundial do Comercio (OMC), que passou a existir na pratica a partir de 1995. O objetivo da Organização era institucionalizar o debate sobre comercio mundial e ser um fórum para solução de disputas comerciais. O Acordo TRIPS, cabe recordar, compõe o Anexo 1-C do Acordo Geral da OMC e visa a completar as deficiências do sistema da Organização Mundial da Propriedade Intelectual (OMPI) e vincular definitivamente os direitos de propriedade intelectual ao comércio internacional. Suas disposições constituem padrões mínimos de proteção que devem ser adotados pelos Estados-membros em suas legislações nacionais. Para o TRIPS, a expressão propriedade intelectual abarca todos os aspectos da propriedade intelectual: direito do autor e direitos conexos, marcas, indicações geográficas, desenhos industriais, patentes, topografia de circuitos integrados e proteção de informação confidencial ${ }^{2}$.

Mesmo durante o período de transição para o TRIPS, os países que já ofereciam alguma proteção aos direitos de patentes para as invenções nacionais, tiveram que, a partir desse momento, estender tais direitos de proteção para todos os países membros da OMC. Países que excluíam alguns

\footnotetext{
${ }^{2}$ BASSO, Maristela. O direito internacional da propriedade intelectual. Porto Alegre: Livraria do Advogado, 2000.
}

Revista Brasileira de Direito Internacional, Curitiba, v.4, n.4, jul./dez.2006 
produtos da proteção por patentes (notadamente produtos farmacêuticos e agrícolas), tiveram que começar a dar-lhes garantia conforme um calendário que varia de acordo com o seu nível de desenvolvimento ${ }^{3}$, mas antes disso já deviam aceitar as aplicações desse processo ${ }^{4}$.

A lei brasileira foi moldada de conformidade com o TRIPS, uma vez que, a partir da promulgação do Decreto n. 1.355 de 1994, todos os princípios e tratados pactuados multilateralmente na Rodada do Uruguai começaram a vigorar no Brasil. Por causa disso, o País teve que adaptar todas as suas leis concernentes à biotecnologia, por exemplo. Esse processo de adaptação não foi linear nem ocorreu pacificamente; ao contrário, foi extremamente influenciado pelo cenário internacional. $O$ projeto de lei da propriedade industrial foi enviado ao Congresso em 1991, com pedido de urgência; apesar disso, só foi aprovado em 1996. Os pontos controvertidos do debate em relação ao projeto de lei referiam-se à inclusão no ordenamento jurídico pátrio da possibilidade de patenteamento de produtos produzidos a partir da química fina e dos biotecnológicos. ${ }^{5}$

Até 1997, quando entrou em vigor a Lei de Patentes, o Brasil não respeitava patentes farmacêuticas internacionais, apoiando-se na Convenção de Paris de 1883. A partir daí, as leis 9.279/96 e 9.456/96 passaram a disciplinar a proteção à biotecnologia ${ }^{6}$ e todos os laboratórios ficaram proibidos de copiar medicamentos até o vencimento do direito de patente, que é de 20 anos.

Vale lembrar que a Índia perdeu um painel ${ }^{7}$ requerido pelos $E U A^{8}$ em $1996^{9}$ por não ter cumprido a determinação do $\operatorname{TRIPS}^{10}$ de aceitar, a partir de

\footnotetext{
${ }^{3}$ O prazo para países em menor desenvolvimento relativo é 2016, em decorrência do previsto no artigo 66 do próprio TRIPS. (WORLD TRADE ORGANIZATION INFORMATION AND MEDIA RELATIONS DIVISION. Uderstanding the WTO. Genève: World Trade Organization Information and Media Relations Division, 2005).

${ }^{4}$ O Chamado Mailbox System, que é a maior fonte de problemas dos membros no processo de adaptação ao TRIPS (WT/COMTD/W/77).

${ }^{5}$ BARRAL, Weber. O Brasil e a OMC. Curitiba: Juruá, 2002. ${ }^{6}$ Id.

${ }^{7}$ Segundo o painel, a Índia não cumpriu as obrigações dos artigos 70.8(a), 63 (1) e (2) e 70.9 do TRIPS.

${ }^{8}$ A Comunidade Européia ingressou no painel como terceira parte.

${ }^{9} \mathrm{O}$ pedido de consulta que deu origem à disputa ocorreu em 2 de julho de 1996 e o painel foi estabelecido em 20 de novembro daquele ano.
}

Revista Brasileira de Direito Internacional, Curitiba, v.4, n.4, jul./dez.2006 
janeiro de 1995 , a requisição de direitos exclusivos de comercialização ${ }^{11}$ de produtos farmacêuticos. Essa era uma obrigação decorrente de uma norma transitória estabelecida pelo artigo 65 do TRIPS para todos os membros da OMC que à época ainda não protegiam através de patentes os produtos farmacêuticos. A Índia acabou sendo um dos últimos membros da OMC a adotar essas medidas ${ }^{12}$, visto que nesse país, assim como no $\mathrm{Brasil}^{13}$, os tratados internacionais não são de aplicação imediata.

No caso indiano, o presidente da Índia promulgou em 31 de dezembro a Patents Ordinance, que emendava o Patents Act de 1970 e cumpria com o disposto no TRIPS, garantindo o direito de patente sobre os produtos farmacêuticos (artigo 70.8 (a) e direitos exclusivos de comercialização aos referidos produtos (artigo 70.9). Está Ordinance foi emitida pelo presidente no exercício dos poderes conferidos a ele pelo artigo 123 da constituição indiana, que the permite legislar quando o parlamento (uma ou as duas casas) não estiver em sessão, cumprido requisitos de urgência e necessidade, um espécie de medida provisória. Essa Ordinance entrou em vigor em 1 de janeiro de 1995 e durou até 26 de março daquele ano, uma vez que esse tipo de lei deixa de vigorar seis semanas após 0 inicio das atividades parlamentares. Durante 0 período em que a Ordinance vigorou, 125 pedidos de patentes foram recebidos e arquivados.

O governo tentou aprovar no Parlamento uma Patents Bill para dar efeito permanente a medidas trazidas pela Ordinance, mas, no meio do processo, o Parlamento foi dissolvido, e nessa época expirou a validade da Ordinance. Ou seja, a Índia chegou a ter uma legislação protetora de patentes de fármacos, e, ao deixar de ter, foi diretamente questionada na OMC.

De todos os Acordos da OMC, o TRIPS é o acordo sobre o qual os países ingressantes na Organização têm mais dúvidas e formulam mais questionamentos detalhados sobre todas as áreas por ele cobertas. Os

\footnotetext{
${ }^{10}$ Violação dos artigos $63,64,70.8$ e 70.9 do TRIPS.

${ }^{11} \mathrm{Na}$ prática, são muito similares aos direitos decorrentes de uma patente.

12 Em 1999.

${ }^{13}$ Com as exceções trazidas pela Emenda Constitucional 45.
}

Revista Brasileira de Direito Internacional, Curitiba, v.4, n.4, jul./dez.2006 
questionamentos dizem respeito à promulgação da legislações necessária, seu escopo e aplicabilidade e especialmente sua conformidade com o TRIPS.

No decorrer do processo, os países ingressantes também devem descrever o seu sistema de proteção de propriedade intelectual, demonstrando as sua efetividade ${ }^{14}$. Na verdade para muitos países, mais difícil que incorporar o TRIPS à sua legislação interna, é dar efetividade às novas regras, assim como criar processos de registros fáceis, descomplicados, não excessivamente caros e, contudo, também eficientes ${ }^{15}$.

\section{TRIPS E CDB}

Uma das discussões atuais sobre o TRIPS tem se concentrado na sua relação com a Convenção sobre Diversidade Biológica (CDB). A questão que se põe é a seguinte: o TRIPS obriga o requerente de uma patente a revelar o país de origem e as fontes de qualquer material genético ou conhecimento tradicional utilizado no processo de pesquisa e desenvolvimento (P\&D) de uma invenção e como pretende compartilhar os benefícios resultantes da comercialização com o país ou comunidade de origem e transformar os conhecimentos tradicionais em uma categoria de propriedade intelectual ${ }^{16}$.

Originalmente os recursos genéticos da biodiversidade e os conhecimentos tradicionais eram regulados no plano internacional pela $\mathrm{CDB}^{17}$ da Organização das Nações Unidas (ONU) assinada no Rio de Janeiro, como resultado da ECO-92 ${ }^{18}$ (art. 8j, 15.1 e seguintes).

\footnotetext{
${ }^{14}$ UNITED NATIONS CONFERENCE ON TRADE AND DEVELOPMENT. WTO accessions and development policies. New York and Geneva: United Nations, 2001. p. 208-209.

${ }^{15}$ WORLD TRADE ORGANIZATION INFORMATION AND MEDIA RELATIONS DIVISION. Uderstanding the WTO. Genève: World Trade Organization Information and Media Relations Division, 2005. p. 43.

${ }^{16}$ ICTSD. Série Briefing da Rodada de Doha: Actualização para Hong Kong. 2005. v. 4. [Online]. Disponível em: <http://www.ictsd.org>. Acesso em: nov. 2005. p. 25

${ }_{17}$ Adota pelo Brasil através do Decreto Legislativo 2 de 1994.

18 GERHARDSEN, Tove Iren S. Brazil, Índia get developed country support for TRIPS amendment on biodiversity. Intelectual Property Watch. [Online]. Disponível em: <http://www.ipwatch.org>. Acesso em: 15 jun. 2006.
}

Revista Brasileira de Direito Internacional, Curitiba, v.4, n.4, jul./dez.2006 
A CBD prevê a divisão dos benefícios trazidos entre o provedor da fonte genética e aquele que detém Consentimento Prévio Fundamentado ${ }^{19}$ para explorá-la.

A CDB é anterior ao TRIPS e tem como objetivo a preservação da diversidade biológica, o uso sustentável de seus componentes a repartição eqüitativa e justa dos benefícios oriundos da utilização da biodiversidade.

A proteção e o uso dos conhecimentos tradicionais ${ }^{20}$, conforme a CDB, podem ser prejudicados com o aumento inadequado das patentes sobre essa espécie de invenção. As relações entre o TRIPS e a CDB devem levar em conta que a evolução da tecnologia não pode pôr em risco o desenvolvimento sustentável e o uso racional dos recursos genéticos da biodiversidade. $O$ objetivo atual é aplicar os dois acordos de maneira complementar.

$\mathrm{O}$ artigo 27.3b do TRIPS permite o patenteamento de processo nãobiológicos e microbiológicos, e determina que os membros protejam as variedades de vegetais por patente ou por um sistema suis generis eficaz ou ainda por um sistema híbrido.

Muitas vezes esses processos são de conhecimento das comunidades tradicionais de países não-desenvolvidos e patenteados de maneira ilegal ou ilegítima em países desenvolvidos. O parágrafo 19 da Declaração de Doha determinou que o Conselho do TRIPS incluísse na sua agenda a revisão desse artigo, a fim de examinar a relação entre o TRIPS e a CDB, guiando-se pelos principio estabelecidos nos artigos 7 e 8 do próprio TRIPS, para que a proteção ao conhecimento tradicional e ao folclore, conforme estabelecidas na CDB, não possam vir a ser desrespeitadas com base no TRIPS. De acordo com Basso ${ }^{21}$, "uma das maiores preocupações dos países em desenvolvimento é justamente a concessão de patentes para invenções que utilizem material genético e conhecimento tradicional, assim como déficit de observância da Convenção pelos países membros da OMC."

${ }^{19}$ CDB. Convenção sobre Diversidade Biológica. Conservação da Diversidade Biológica - Art. 15.5. [Online]. Disponível em: $<$ http://www.direitoshumanos.usp.br/counter/Onu/MeioAmbiente/texto/agenda21/Cap_15.html>. Acesso em: nov. 2006.

${ }^{20}$ São os conhecimentos coletivos das comunidades tradicionais.

21 BASSO, Maristela. Propriedade intelectual na era pós-OMC. Porto Alegre: Livraria do Advogado, 2005. p. 81.

Revista Brasileira de Direito Internacional, Curitiba, v.4, n.4, jul./dez.2006 
Em suma, a preocupação envolvendo os dois acordos internacionais é o fato de o TRIPS permitir o patenteamento de invenções que usem recursos genéticos da biodiversidade,e que não atende as provisões da CDB com relação ao consentimento prévio fundamentado e a repartição eqüitativa e justa dos benefícios oriundos da utilização da biodiversidade.

Outro grande ponto de impasse para a harmonização dos dois tratados é a divulgação da origem do conhecimento tradicional ${ }^{22}$.

Atualmente na OMC existem dois entendimentos entre os membros, que não se excluem mutuamente, com relação à coexistência dos dois acordos. O primeiro defende a solução nacional para o problema, pela qual cada estado regulamentaria as questões de acesso aos recursos genéticos da biodiversidade de seu território, como se daria a repartição eqüitativa e justa dos benefícios oriundos da utilização da biodiversidade, e como seriam elaborados os contratos. A outra solução defendida é uma emenda ao TRIPS, criando regras mínimas para serem seguidas pelos ordenamentos jurídicos nacionais para que seja possível a concessão de patentes de recursos biológicos e os contratos de transferência, devendo as controvérsias ser dirimidas em outro fórum que não a $\mathrm{OMC}^{23}$.

\section{TRIPS E SAÚDE PÚBLICA}

A discussão sobre propriedade intelectual em saúde pública, particularmente sobre a produção de medicamentos, tem por patamar legal o conjunto das disposições sobre patentes que o TRIPS disciplina pelo disposto na Seção 5 da Parte II artigos 27 a 34, a serem analisadas com as regras das partes 5 e 7 do mesmo Acordo.

\footnotetext{
22 OLIVA, Maria Julia. El párrafo 19 de la Declaración de Doha ¿Un paso adelante para el respaldo mutuo entre el Acuerdo sobre los ADPIC y el CDB? Puentes entre el comercio y el desarrollo sostenible, ICTSD, Ginebra, v. 5, n. 5, p. 13, sep./dic. 2004. [Online]. Disponível em: $<$ http://www.ictsd.org/monthly/puentes>. Acesso em: nov. 2006.

${ }^{23} \mathrm{IP} / \mathrm{C} / \mathrm{W} / 368 /$ Rev.1.
}

Revista Brasileira de Direito Internacional, Curitiba, v.4, n.4, jul./dez.2006 
A licença compulsória ${ }^{24}$ prevista no artigo 31 do TRIPS é a licença de uso sem o consentimento do titular da patente, que pode ser concedida sempre que a empresa proprietária exercer, de forma abusiva, seus direitos de patente. Em casos de emergência nacional e interesse público, também é facultada a concessão de licença compulsória. Dessa forma, o laboratório farmacêutico receberia a título de royalties um quantum considerado justo pelo Estado que licenciou compulsoriamente uma patente de oficio, ato que vem sendo denominado de "quebra de patente" pelos laboratórios internacionais produtores de fármacos.

Uma licença compulsória pode ser utilizada para permitir que terceiros produzam o medicamento de forma a prover o mercado mais rapidamente ou torná-lo mais acessível ao público ${ }^{25}$. O Brasil não fez até este momento o uso desse dispositivo; sempre usou a possibilidade do licenciamento compulsório como forma de pressão, para a indústria ${ }^{26}$ ceder nas negociações de preço e produzir alguns medicamentos aqui, com o aval (licenciamento voluntário) dos detentores da patente, pagando os royalties devidos ${ }^{27}$. Mas nunca chegou a autorizar a produção nacional.

A Declaração de Doha sobre o TRIPS e Saúde Pública, de 14 de novembro de $2001^{28}$, tornou ponto pacífico a disposição dos governos signatários de combater as epidemias e outras doenças que afetam os países pobres, reafirmando a possibilidade de utilização do licenciamento compulsório

\footnotetext{
${ }^{24}$ O TRIPS não faz referência à expressão licença compulsória, amplamente utilizada nos direitos internos. Opta pela expressão "outros usos sem autorização do titular dos direitos objeto da patente" (BASSO, Maristela. O direito internacional da propriedade intelectual. Porto Alegre: Livraria do Advogado, 2000).

${ }^{25}$ Mitelman ao comentar o artigo 45 da Lei Argentina de Patentes de Invenções, que trata do licenciamento compulsório por motivo de ordem pública (emergência sanitária ou segurança nacional), compara-o à expropriação, apesar de ambos institutos se darem por meios diversos. Para ele, a licença compulsória nos casos de ordem pública atua como um remédio legal ante uma necessidade social concreta, em relação a um invento em particular (no nosso caso, um medicamento para evitar uma pandemia). (MITELMAN, Carlos Octavio. Cuestiones de derecho industrial. Buenos Aires: AD-HOC, 1999).

${ }^{26}$ No caso brasileiro, principalmente os fabricantes de medicamentos que integram o coquetel anti-AIDS. EUA e Canadá já ameaçaram a detentora do Cyprobay (Bayer), utilizado contra o Anthrax.

${ }_{27}^{27}$ UNIVERSIDADE DE SÃO PAULO [Online]. Disponível em: $<$ http://www2.usp.br/canalacontece/frame.php?canal=../canalacontece/\&conteudo=../busca.php ?key=compulsório $>$. Acesso em: 10 dez. 2004.

${ }^{28} \mathrm{Em}$ novembro de 2001, os EUA juntaram-se ao grupo liderado por Brasil e Índia, formado por 51 países, para aprovar essa resolução da OMC.
}

Revista Brasileira de Direito Internacional, Curitiba, v.4, n.4, jul./dez.2006 
de medicamentos em casos de emergência ou urgência nacional, respeitado o previsto no artigo $31 \mathrm{~b}$ do TRIPS ${ }^{29}$.

O problema é que, à época da Declaração de Doha, os únicos países em desenvolvimento que dispunham de capacidade industrial no setor farmacêutico para fazer uso no disposto na Declaração, eram a África do Sul, o Brasil, a Índia, o Quênia e a Tailândia ${ }^{30}$. Os demais países em desenvolvimento e menor desenvolvimento relativo só teriam uma solução para o seu problema a partir de uma interpretação solidária da decisão do Conselho do TRIPS de 30/08/2003 (WT/L/540), que autoriza a qualquer membro a exportação de produtos farmacêuticos produzidos sob licença compulsória, dentro dos termos por ela fixados, permitindo, por via de conseqüência, a importação desses produtos, mediante notificação ao Conselho do TRIPS. A decisão proíbe a reexportação para países que não se enquadrem nas condições estabelecidas e acaba por flexibilizar o artigo 31, f, do TRIPS, permitindo que os países subdesenvolvidos ou em desenvolvimento que tenham efetuado uma licença compulsória, exportem medicamentos para um outro país que teria o direito de efetuar a licença compulsória, mas sem condições tecnológicas de produção.

Em 6 de dezembro de 2005, o Conselho Geral da OMC tornou essa decisão uma emenda permanente ao TRIPS (IP/C/41), que entra em vigor quando dois terços dos membros da OMC a ratificarem. O prazo dado para isso estende-se até 1.을 de dezembro de $2007^{31}$.

Como bem afirmou o ex-presidente da GSK (Glaxo Smith Kline), Sir Richard Sykes, em discurso ao Royal Institute of International Affairs, em 14 de março de 2002 em Londres:

29 PRESIDÊNCIA da República. Art. 71. Lei no 9.279, de 14 de maio de 1996. [Online]. Disponível em: <https://www.planalto.gov.br/ccivil_03/Leis/L9279.htm>. Acesso em: nov. 2006..

${ }^{30}$ LECOURIEUX, Alain. Esas patentes que matan. Le Monde Diplomatique, Buenos Aires, v. 7 , n. 78, p. 16, dez. 2005.

${ }^{31}$ A emenda é dividida em três partes. A primeira, na forma de Artigo 31 bis, permite que produtos farmacêuticos produzidos sob licença compulsória possam ser exportados para países sem capacidade de produzi-los, por meio de acordos regionais envolvendo países com menor grau de desenvolvimento, entre outros. A segunda parte trata de como evitar a dupla remuneração do detentor da patente; e a terceira consiste em sete parágrafos anexos ao TRIPS, que dispõem sobre os termos de uso do sistema e cobrem questões como definições, notificações e disposições para evitar que os fármacos acabem nos mercados errados, e dispositivos sobre revisões anuais. A emenda também mantém o apêndice ao anexo da decisão de 2003, que define as condições que tornam um país elegível como importador.

Revista Brasileira de Direito Internacional, Curitiba, v.4, n.4, jul./dez.2006 


\begin{abstract}
Não acredito que o TRIPS impeça que outros países em desenvolvimento, tais como Brasil e Índia, obtenham acesso aos medicamentos que necessitam. Pelo contrário, creio firmemente que esses países tem a capacidade de desenvolver suas próprias industrias farmacêuticas baseadas na pesquisa, além de outras indústrias inovadoras, mas isso só ocorrerá quando ofereçam a proteção de PI consagrada no TRIPS. O TRIPS necessita ser reconhecido como uma ferramenta importante para o desenvolvimento industrial dos países em desenvolvimento. ${ }^{32}$
\end{abstract}

\begin{abstract}
Atualmente, o medo da gripe aviária se torna mais intenso principalmente pelo fato de estar protegido por patente mundial o único medicamento (Tamiflu) que combate o H5N1, dos Estados Unidos ${ }^{33}$ aos países mais pobres do mundo. Mais que o preço do medicamento, o temor decorre da dúvida se o laboratório suíço Roche, produtor do Tamiflu, tem condições de produzir o medicamento em quantidades suficientes para abastecer os estoque mundiais. ${ }^{34}$ A Roche produz o único remédio eficaz contra a gripe aviária, mas não tem condições de produzi-lo em quantidade suficiente para abastecer o mundo inteiro.

O ganho financeiro é um estímulo insubstituível para a pesquisa e para a produção de novos remédios. Tanto assim é que os grandes laboratórios são, com freqüência, acusados de não se dedicarem à malária porque a grande maioria de suas vítimas se concentra em países pobres ${ }^{35}$. No caso em tela, o
\end{abstract}

\footnotetext{
${ }^{32}$ CORREA, Carlos Maria (Dir.). Temas de derecho industrial y de la competência: propiedad intelectual y políticas de desarrollo. Buenos Aires: Editorial Ciudad Argentina, 2005. p. 99.

${ }^{33} \mathrm{Em} 2005$ o presidente americano conseguiu aprovar o orçamento de um plano bilionário contra a gripe aviária. Um bilhão de dólares foram destinados a compra de Tamiflu, três bilhões de dólares foram destinados à pesquisa e ao desenvolvimento de uma vacina para o vírus pandêmico (transmissível entre humanos) e outro bilhão de dólares para desenvolvimento de planos de emergência. (NEIVA, Paulo; BERGAMO, Giuliana. Nas asas do pânico. Revista Veja, p. 90, 8 mar. 2006).

${ }^{34}$ LECOURIEUX, Alain. Esas patentes que matan. Le Monde Diplomatique, Buenos Aires, v. 7, n. 78, p. 16, dez. 2005.

${ }^{35}$ Nos últimos 25 anos foram desenvolvidos mais de cem medicamentos contra doenças cardíacas, ao passo que no mesmo período não foram desenvolvidos mais do que uma dúzia de medicamentos contra doenças típicas de países pobres, tais como malária, chagas, etc., cujas vítimas em sua maioria, não têm como pagar pelo tratamento, tão pouco seus governos, o que vai contra a lógica do lucro (GRAU-KUNTZ, Karin. Dignidade humana e direito de patentes: sobre o problema do acesso a medicamentos. In: CARVALHO, Patrícia Luciane de. Propriedade Intelectual: estudos em homenagem à professora Maristela Basso. Curitiba: Juruá, 2005. p. 309). Como afirma Vargas, a pesquisa farmacêutica não é atividade filantrópica e "é um erro atribuir ao mercado a função de suprir as demandas de saúde pública". (VARGAS, Fábio Aristimunho. O regime internacional de proteção do acesso a medicamentos: um enfoque
}

Revista Brasileira de Direito Internacional, Curitiba, v.4, n.4, jul./dez.2006 
fato de o H5N1 ser uma ameaça a todas as nações do mundo, ricas e pobres, o ganho financeiro está garantido, uma vez que os países ricos também compraram o medicamento, compensando um eventual licenciamento compulsório por um país pobre que não tenha condições de arcar com o custo. Por outro lado, diante da possibilidade do detentor da patente não ter capacidade de produzir quantidade suficiente de medicamentos, o eventual licenciamento compulsório não se daria por questões financeiras, ${ }^{36}$ e também, não ocorreria apenas em países com menor grau de desenvolvimento. Aliás, ocorreria, mormente em países desenvolvidos ou em desenvolvimento, com a tecnologia necessária para produzir o medicamento localmente e ensejaria uma aplicação da emenda ao TRIPS, aprovada em dezembro de 2005, para que os países sem condições de produzir localmente esse medicamento possam importar o genérico de um país detentor da tecnologia.

Ademais, deve-se ter em conta que, apesar de a proteção patentária estar presente na maior parte dos países em desenvolvimento, devido aos seus altos custos, em alguns países considerados como mercados pequenos, de capacidade tecnológica limitada, com baixo risco de violação da patente, as multinacionais farmacêuticas não fazem o pedido de patente de todos os medicamentos. Em seu estudo "Do patents for Antiretroviral Drugs Constrain Access to AIDS Treatment in África?", Amir Attran e Lee Gillespie-White revelam que em 13 dos 53 países onde foi realizado o estudo não havia registro de patente das 15 drogas pesquisadas. O mesmo deve se repetir no caso de alguns países em relação à gripe aviária..$^{37,38}$

\section{ACORDOS PÓS-TRIPS}

social. In: CARVALHO, Patrícia Luciane de. Propriedade Intelectual: estudos em homenagem à professora Maristela Basso. Curitiba: Juruá, 2005. p. 318).

${ }^{36}$ Elevado preço o medicamento.

37 ATTRAN, Amir; GILLESPIE-WHITHE, Lee. Do patents for Antiretroviral Drugs Constrain Access to AIDS Treatment in África. The Journal of the American Medical Association - JAMA, v. 286, n. 15, 17 out. 2001. [Online]. Disponível em: <http://jama.ama-assn.org>. Acesso em: 27 jan. 2006.

${ }^{38}$ Com a aprovação da emenda ao TRIPS em dezembro de 2005, é muito provável que essa situação mude a partir da entrada em vigor da emenda em dezembro de 2007.

Revista Brasileira de Direito Internacional, Curitiba, v.4, n.4, jul./dez.2006 
Depois que foi concluído o TRIPS, que do ponto de vista dos países desenvolvidos apenas fixou padrões mínimos de proteção à propriedade intelectual, surgiram (ou continuaram) as tentativas bilaterais de impor padrões mais rígidos de proteção à propriedade intelectual.

Diante da necessidade de países em menor desenvolvimento relativo e em desenvolvimento de obterem ajuda financeira junto aos países desenvolvidos, esses últimos passaram a condicionar a concessão dessa ajuda ao aumento dos níveis de proteção à propriedade intelectual nos países beneficiados. Esse acordos são os acordos bilaterais ou regionais de livre comércios (FTAs) e os acordos bilaterais de investimentos (BITs).

Essas medidas mais duras de proteção colocam em risco o desenvolvimento sustentável e o acesso à saúde nos países que acabam por adotá-las, extinguindo as flexibilidades que Ihes eram garantidas pelo TRIPS, ferindo inclusive o acordado na Declaração de Doha. Esses países também perdem competitividade no mercado internacional, pois os altos níveis de proteção da propriedade intelectual asseguram vantagens para os países desenvolvidos ${ }^{39}$.

Para Basso,

\begin{abstract}
Não há duvidas que os FTAs e BITs, na era pós-TRIPS, constituem instrumentos potenciais por meio dos quais países desenvolvidos impões novas obrigações de propriedade intelectual aos países em desenvolvimento, Em vez de utilizarem a OMC e a OMPI para novas negociações, os FTAs e os BITs estimulam e impões uma nova agenda expansionistas capaz de assegurar um sistema global de propriedade intelectual 'TRIPS-plus' e' TRIPS-extra'. ${ }^{40}$
\end{abstract}

Os Acordos TRIPS-plus seriam aqueles que implicam em compromisso que vão além do determinado pelo TRIPS, que restringem ou anulam flexibilidades previstas no acordo da OMC, ou, enfim, disciplinam

\footnotetext{
${ }^{39}$ Os EUA tem convencido seus parceiros nos FTAS a incluir uma proteção maior para dados de ensaios farmacêuticos, o que provavelmente atrasará o lançamento de versões genéricas de medicamentos no mercado (ICTSD. Série Briefing da Rodada de Doha: Actualização para Hong Kong. 2005. v. 4. p. 26. [Online]. Disponível em: <http://www.ictsd.org>. Acesso em: nov. 2005).

40 ICTSD. Série Briefing da Rodada de Doha: Actualização para Hong Kong. 2005. v. 4. p. 12. [Online]. Disponível em: <http://www.ictsd.org>. Acesso em: nov. 2005.
}

Revista Brasileira de Direito Internacional, Curitiba, v.4, n.4, jul./dez.2006 
matérias não abordadas por ele. Essas medidas são tomadas basicamente através de 3 instrumentos:

1) forum shifting ${ }^{41}$

2) estratégias que evitem a solução de controvérsias nos sistemas OMC/OMPI;

3) manutenção do principio do minimum standards. ${ }^{42}$

O problema é que, ainda que não firam o TRIPS, esse acordos que estabelecem padrões mais altos não são, a rigor, bilaterais, pois esses padrões acabam, por força da Cláusula da Nação Mais Favorecida, se estendendo a todos os países membros da OMC. Em especial, os acordos TRIPS-plus firmados pelo EUA, tornam sem efeito as previsões dos artigos 7 e 8 do TRIPS ${ }^{43}$.

Em suma, em comparação com os acordos TRIPS-plus, o TRIPS original é a melhor opção para os países não-desenvolvidos ${ }^{44}$. Em que pese, em FTAs recentes com os EUA, Tailândia e Comunidade Andina formularam primeiro pedido de TRIPS-plus sugerindo que a revelação de recurso genético ou conhecimento tradicional seja parte do critério para requisição de patentes ${ }^{45}$.

\section{CONSIDERAÇÕES FINAIS}

\footnotetext{
${ }^{41}$ Buscar alternativas fora dos sistemas da OMC/OMPI, que permitam a adoção de novas agendas, novos padrões de proteção, sem ofender o já acordado no âmbito das duas organizações.

${ }^{42}$ Com a adoção desse princípio, cada novo acordo não revoga o anterior; apenas aumenta os padrões mínimos nele estabelecidos para padrões mais elevados, chamados de better standards.

${ }_{43}$ Por exemplo, o acordo EUA-Singapura.

${ }^{44} \mathrm{Em}$ que pese a maioria dos Acordos TRIPS-plus ocorrem entre países desenvolvidos e países não-desenvolvidos, o FTA entre EUA e Austrália contém medidas TRIPS-plus, sendo exemplo de que esse tipo de acordo também ocorre entre países desenvolvidos (ESTRELLA, Ângela T. Gobbi. TRIPS e medicamentos - $2^{\circ}$ Round: Compatibilidade da exigência de certificação australiana com o TRIPS e as regras TRIPS-plus do Acordo de Livre-Comércio Austrália - Estados Unidos (AUSFTA). In: CARVALHO, Patrícia Luciane de. Propriedade Intelectual: estudos em homenagem à professora Maristela Basso. Curitiba: Juruá, 2005. p. 239).

${ }^{45}$ ICTSD. Série Briefing da Rodada de Doha: Actualização para Hong Kong. 2005. v. 4. p. 26. [Online]. Disponível em: <http://www.ictsd.org>. Acesso em: nov. 2005.
}

Revista Brasileira de Direito Internacional, Curitiba, v.4, n.4, jul./dez.2006 
O TRIPS é útil para que os países em desenvolvimento e em menor grau de desenvolvimento possam desenvolver-se e alavancar uma indústria e uma tecnologia locais, pelo menos no setor farmacêutico. Ademais, podem serIhes de grande utilidade em casos de pandemias. Mas esse exemplo pode e deve ser aplicado em outros setores da indústria.

Em que pesem as regras de proteção à propriedade intelectual estabelecidas no TRIPS parecerem, à primeira vista, severas demais para os países não-desenvolvidos e por mais que a idéia de produzir remédios livremente como faziam antes thes parecesse mais atrativa, a longo prazo 0 reflexo desse desrespeito à propriedade intelectual seria desastrosos para todos, pela retração dos investimentos da indústria farmacêutica no desenvolvimento de novas drogas. Ademais, essas regras forçam os estados a desenvolverem tecnologias farmacêuticas próprias e os ensina a lucrar com elas.

A exploração econômica do conhecimento, por meio da proteção de patentes, não só premia o talento e a dedicação dos inventores como também é útil ao crescimento econômico e ao desenvolvimento tecnológico das nações, garantindo o reinvestimento em pesquisa para a descoberta de novos produtos úteis à coletividade e para a cura de doenças que afligem toda a humanidade. A política de proteção de patentes prevista no TRIPS resulta numa elevação dos investimentos em pesquisa científica, com reflexo no aumento do número de cientistas e de descobertas úteis ao desenvolvimento social.

Como já foi dito, em comparação com a maioria dos Acordos TRIPSplus, o TRIPS continua sendo a melhor opção para os países em desenvolvimento e em menor grau de desenvolvimento relativo. Os Acordos TRIPS-plus só passam a ser interessantes para estes últimos quando o plus significa a sobreposição das previsões da CBD ao artigo 27.3 do TRIPS. Mas, como isso é pouco provável, cabe a esses países, lutaram na OMC por uma emenda ao TRIPS que garanta uma interpretação harmônica entre os dois tratados.

\section{REFERÊNCIAS}

Revista Brasileira de Direito Internacional, Curitiba, v.4, n.4, jul./dez.2006 
ATTRAN, Amir; GILLESPIE-WHITHE, Lee. Do patents for Antiretroviral Drugs Constrain Access to AIDS Treatment in África. The Journal of the American Medical Association - JAMA, v. 286, n. 15, 17 out. 2001. [Online]. Disponível em: <http://jama.ama-assn.org>. Acesso em: 27 jan. 2006.

BARRAL, Weber. O Brasil e a OMC. Curitiba: Juruá, 2002.

BASSO, Maristela. O direito internacional da propriedade intelectual. Porto Alegre: Livraria do Advogado, 2000.

Propriedade intelectual na era pós-OMC. Porto Alegre: Livraria do Advogado, 2005.

CDB. Convenção sobre Diversidade Biológica. Conservação da Diversidade Biológica - Art. 15.5. [Online]. Disponível em:

$<$ http://www.direitoshumanos.usp.br/counter/Onu/MeioAmbiente/texto/agenda2 1/Cap_15.html>. Acesso em: nov. 2006.

CORREA, Carlos Maria (Dir.). Temas de derecho industrial y de la competência: propiedad intelectual y políticas de desarrollo. Buenos Aires: Editorial Ciudad Argentina, 2005.

ESTRELLA, Ângela T. Gobbi. TRIPS e medicamentos - $2^{\circ}$ Round: Compatibilidade da exigência de certificação australiana com o TRIPS e as regras TRIPS-plus do Acordo de Livre-Comércio Austrália - Estados Unidos (AUSFTA). In: CARVALHO, Patrícia Luciane de. Propriedade Intelectual: estudos em homenagem à professora Maristela Basso. Curitiba: Juruá, 2005.

GERHARDSEN, Tove Iren S. Brazil, Índia get developed country support for TRIPS amendment on biodiversity. Intelectual Property Watch. [Online]. Disponível em: <http://www.ip-watch.org>. Acesso em: 15 jun. 2006.

GRAU-KUNTZ, Karin. Dignidade humana e direito de patentes: sobre 0 problema do acesso a medicamentos. In: CARVALHO, Patrícia Luciane de. Propriedade Intelectual: estudos em homenagem à professora Maristela Basso. Curitiba: Juruá, 2005.

ICTSD. Série Briefing da Rodada de Doha: Actualização para Hong Kong. 2005. v. 4. [Online]. Disponível em: <http://www.ictsd.org>. Acesso em: nov. 2005.

LECOURIEUX, Alain. Esas patentes que matan. Le Monde Diplomatique, Buenos Aires, v. 7, n. 78, p. 16, dez. 2005.

MITELMAN, Carlos Octavio. Cuestiones de derecho industrial. Buenos Aires: AD-HOC, 1999. 
NEIVA, Paulo; BERGAMO, Giuliana. Nas asas do pânico. Revista Veja, p. 90, 8 mar. 2006.

OLIVA, Maria Julia. El párrafo 19 de la Declaración de Doha ¿Un paso adelante para el respaldo mutuo entre el Acuerdo sobre los ADPIC y el CDB? Puentes entre el comercio y el desarrollo sostenible, ICTSD, Ginebra, v. 5, n. 5, p. 13, sep./dic. 2004. [Online]. Disponível em:

<http://www.ictsd.org/monthly/puentes>. Acesso em: nov. 2006.

UNITED NATIONS CONFERENCE ON TRADE AND DEVELOPMENT. WTO accessions and development policies. New York and Geneva: United Nations, 2001.

UNIVERSIDADE DE SÃO PAULO. [Online]. Disponível em:

$<$ http://www2.usp.br/canalacontece/frame.php?canal=../canalacontece/\&conteu do=../busca.php?key=compulsório $>$. Acesso em: 10 dez. 2004.

VARGAS, Fábio Aristimunho. O regime internacional de proteção do acesso a medicamentos: um enfoque social. In: CARVALHO, Patrícia Luciane de.

Propriedade Intelectual: estudos em homenagem à professora Maristela Basso. Curitiba: Juruá, 2005.

WORLD TRADE ORGANIZATION INFORMATION AND MEDIA RELATIONS DIVISION. Uderstanding the WTO. Genève: World Trade Organization Information and Media Relations Division, 2005. 